\title{
Art to Science: Tools for Greater Objectivity in Resource Monitoring
}

\section{By D. Terrance Booth and Samuel E. Cox}

\section{The Ne} management (Fig. 1).

Now, our monitoring needs are different and the importance of objective data consistent with formal scientific inquiry is more essential; the goal is " ... consistent, uniform, and standard vegetation attribute sampling that is economical, repeatable, statistically reliable, and technically adequate." From discussions with agency personnel, and through our own experience and reading, we believe meeting this goal has been mostly impractical due to: 1) the variation in data collected among observers and through time by single observers; 2) the high cost of conventional monitoring, which results in a) limited sampling, resulting in a high risk of false-negative results (i.e., finding no change, when change has occurred), and b) subjective selection of relatively small "representative" sample areas with a focus on specific resources rather than ecological systems ${ }^{2}$; and 3) a lack of statistical design and rigor in inventory and monitoring efforts.

These obstacles to effective data collection result from inventory and monitoring (i.e., surveys) technologies unsuited to a vast resource; from stresses on observers; and from shrinking budgets and limited survey workforce. Expert rangeland technicians recognize the importance of plant growth-stage (phenology) comparability when making across-year comparisons. However, the number of sample sites that can be visited and worked, using conventional survey methods during phenologically comparable time frames of a given year, is limited. Usually, there is inadequate time for a statistical science-based resource survey of extensive areas. In practice, conventional rangeland data collecting continues to be unverifiable, often highly variable, and from a limited number of nonrandomly selected sites. It simply has not been practical to do otherwise. ${ }^{3}$

The past decade has produced a number of new tools and methods for improving natural resource monitoring. The arrival of dependable digital cameras and the development of tools for using these cameras and resulting imagery are among the most important of these advances. Here we review the use of nadir (vertical) digital imagery and associated tools to highlight how these advances are making resource surveys more objective and adequate sampling and data acquisition more practical for landscape-scale management.

\section{The Quest}

If there has been a "holy grail" of ecological investigation, it is image-based data collection. As early as 1924, Cooper ${ }^{4}$ described a camera stand for use in vegetation analysis (Fig. 2a). His work signaled that ecological imaging had moved past the landscape perspectives of late 19th and early 20th century photographers such as W. H. Jackson and H. L. Shantz, to the nadir perspective useful for measurements. Cooper's work was followed by an 80-year series of reports on very high-resolution imaging for detailed ecological analysis; but, it is only now, with the widespread use of digital cameras, that image-based methods for acquiring fine-scale information are replacing conventional point, plot, transect, and ocular estimates in ecological-monitoring tool boxes.

\section{Photo Sampling}

Methods for obtaining nonaerial, nadir digital images include staffs, stands (Figs. 2b and 2c), booms, and gantries, plus mounts for all-terrain vehicles and automobiles; also, there is a recently described free-hand method $^{6}$ (Fig. 2d). These tools allow for a range of camera positions above ground level and respective image resolutions.

Image locations should be documented with a Global Positioning System (GPS) ${ }^{5}$ and images can be cropped to a desired area of interest before analysis. If a square area of interest is desired, a 3:4 aspect ratio will reduce image cropping compared to a more rectangular ratio (aspect ratio is the width:length of the digital-camera sensor).

Even where sampling is done primarily from aircraft, acquisition of ground images is an important part of monitoring. 


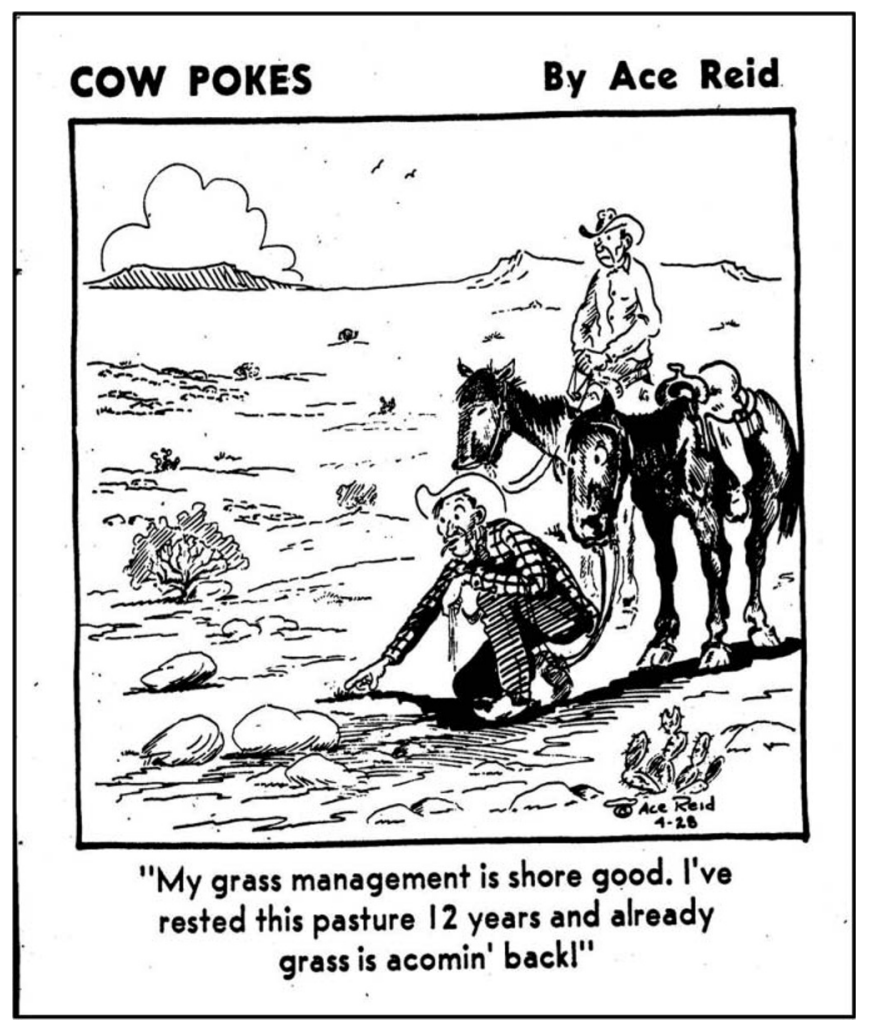

Figure 1. Ace Reid on "ocular" estimates (reprinted with permission from Ace Reid Enterprises/Cowpokes Cartoons).

It provides technicians the opportunity to capture sharper nadir images than can be obtained from the air and to make notes that will help with species identification and the interpretation of other fine detail during image analysis. The use of vehicle platforms - aerial or wheeled-may be regarded as an economical means of extending, but not totally replacing, stationary ground sampling and observation.

The images are samples only. They mean little without a carefully crafted plan incorporating critical thinking and experimental design appropriate to testing one or more hypotheses (e.g., a null hypothesis of no ecologically important change over time). West ${ }^{7}$ emphasized the importance of rangeland surveys as " ... science-based tests ... used to fine tune the management and put it on a more objective basis" (our emphasis). He stressed that a "crucial" first step in planning is written statements defining the questions to be tested. Image-based rangeland surveys bring the power of true analytical research and we advocate having hypotheses and plans reviewed by consulting statisticians to maximize the information return from landscape-scale rangeland surveys.

The use of Geographic Information Systems (GIS) to draft sampling plans for aerial and ground-image acquisition makes it easier to consider desired sampling intensities, resolutions, and distributions with the realities of budget, ground access, and the complications of aerial acquisition (mountains, prevailing winds, operational and emergency landing sites). It facilitates planning for data storage, considerations of costs for alternative platforms and plans, and the tradeoffs of what management questions can be legitimately addressed with the budget available. Different aircraft have different capabilities and limitations. The capabilities and limitations of available aircraft, and their pilots, should be understood and always respected.

\section{Aerial Sampling}

Platforms being used for aerial-image acquisition in the resolution range of 1 to $50 \mathrm{~mm}$ per pixel (mmpp) include piloted conventional and light sport airplanes (LSAs, Fig. 3a), manned and unmanned helicopters (Fig. 3b), and unmanned fixed-wing aircraft (Figs. 3c and 3d). Surprisingly, contracting for a piloted LSA generally is the least expensive (M. M. Fladeland, personal communication, NASA Ames Research Center, Moffett Field, CA, August 2008; presentations and discussions at the Symposium: Very High Resolution Imaging for Resources Monitoring, SRM Annual Meeting, Billings, MT, February 2011). Only LSAs and helicopters can fly slow enough to avoid excessive motion blur when long, heavy camera lenses are being used to acquire image resolutions equal to or greater than 1-mmpp (i.e., 30,000 times greater resolution than Landsat satellite imagery; Fig. 4). Contract costs for manned helicopters usually are more expensive than LSAs but the helicopters (manned and unmanned) can fly in weather and mountain conditions where LSAs cannot be operated safely. Manned helicopters and LSAs carry larger payloads and operate over longer distances than unmanned aerial vehicles. They also can carry multiple cameras allowing for nested, simultaneously acquired multiresolution images (e.g., 1, 10, and $20 \mathrm{mmpp}$ ). This capability allows users to acquire wide fields of view and high resolution, a capability that has been demonstrated as useful in many aerial-monitoring applications including the study of fire intervals in shrubs, ${ }^{8}$ and in monitoring invasive species and disturbed land reclamation (Fig. 5).

Aerial surveys acquiring 1-mmpp imagery overcome the need to depend solely on subjective selection of "representative" study areas. It is now practical to systematically sample watersheds, allotments, and other landscape-scale management units, and to conduct statistical analyses and ecological assessments on that basis.

To summarize, aerial surveys acquiring multiresolution imagery that includes 1-mmpp data have repeatedly demonstrated: 1) lower cost than extensive conventional ground sampling for areas greater than about $200 \mathrm{ha}$; 2) practical acquisition of large sample numbers; 3) reduced sample-collection time; 4) the creation of permanent records for comparison to subsequent surveys; and 5) the capability of capturing details for detecting ecologically important changes.

\section{Image-Based Measurements}

The US Department of Agriculture's Agricultural Research Service (ARS) has developed (and continues to develop) software to facilitate measurements of key ecological indicators from digital imagery. These programs are effective and accurate, but only when used with imagery having resolutions suited 


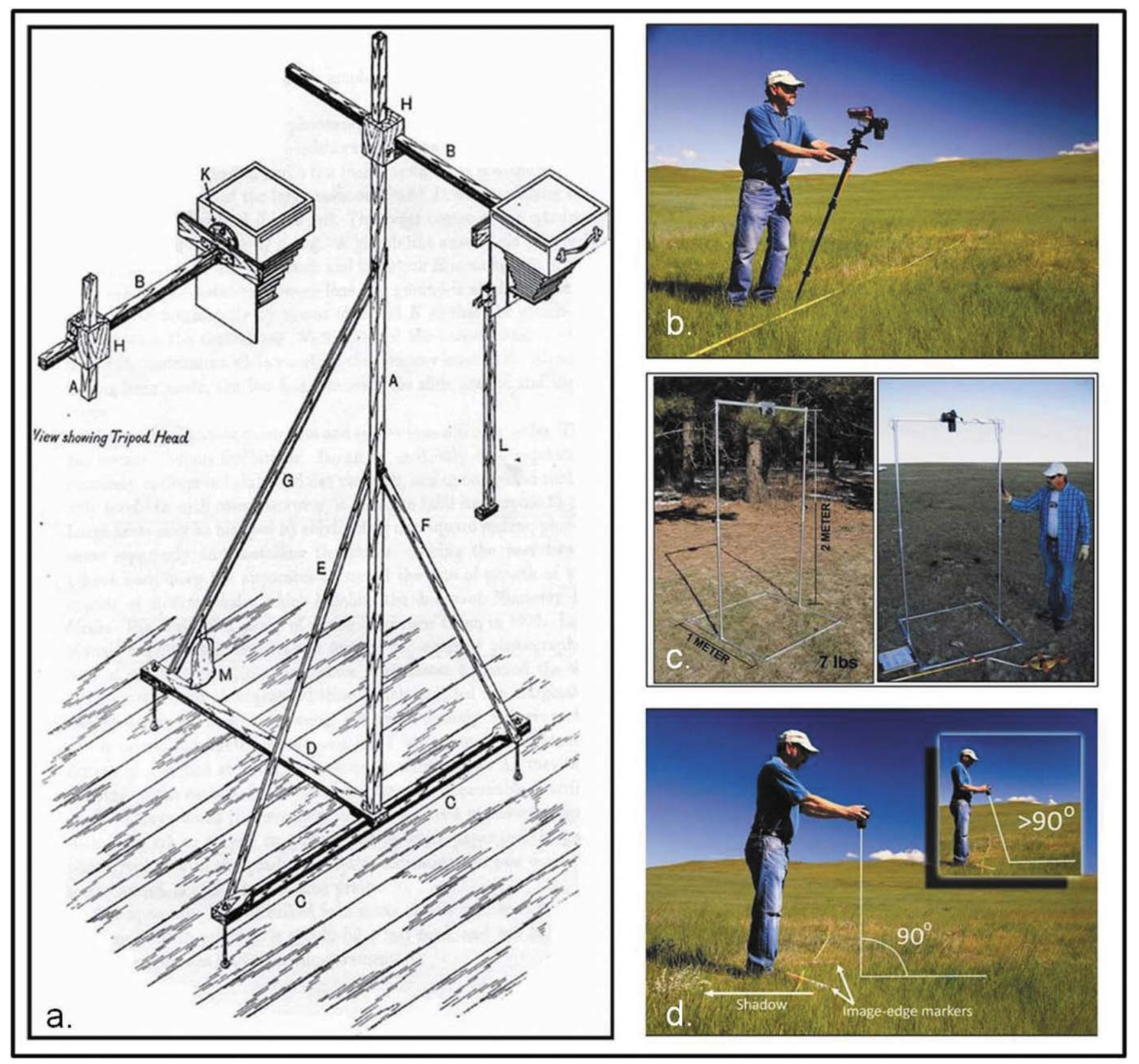

Figure 2. a, Cooper ${ }^{4}$ camera stand (republished with permission). b, Johnson staff. ${ }^{5}$ c, $2-m$, breakdown aluminum stand. d, Cagney ${ }^{6}$ free-hand method. The $d$ inset shows a common error of the free-hand method and why a bubble level is useful (republished with permission).

to the tasks and by people with adequate experience on the ground in the areas of interest. For measuring ground cover, image resolutions should be equal to or greater than 1 mmpp. Attempts have been made to obtain accurate ground-cover measurements from 10-, 20-, and 50-mmpp imagery; however, using 10-mmpp or lower resolution imagery means the sample-point pixels have a $10-\mathrm{mm}$ or greater onthe-ground diameter. ${ }^{9,10, \mathrm{i}}$ That is like point sampling with a

\footnotetext{
See also Booth, D. T., and S. E. Cox. 2009. Dual-camera, high-resolution aerial assessment of pipeline revegetation. Environmental Monitoring and Assessment 158:23-33.
}

walking stick instead of a pin. The result is not a point, but a plot-usually containing multiple ground-cover characteristics - and thus violates the theory of point sampling for ground-cover measurements.

Another important consideration for image-based measurements is the season and related environmental conditions at the time images are acquired. Canopy cover of herbaceous species is a more variable, less robust measurement than is basal cover. Basal cover can be measured by acquiring images in spring before canopy development. However, our experience in cooperative work with public-land management agencies has been that measurement of basal cover has had a lower 


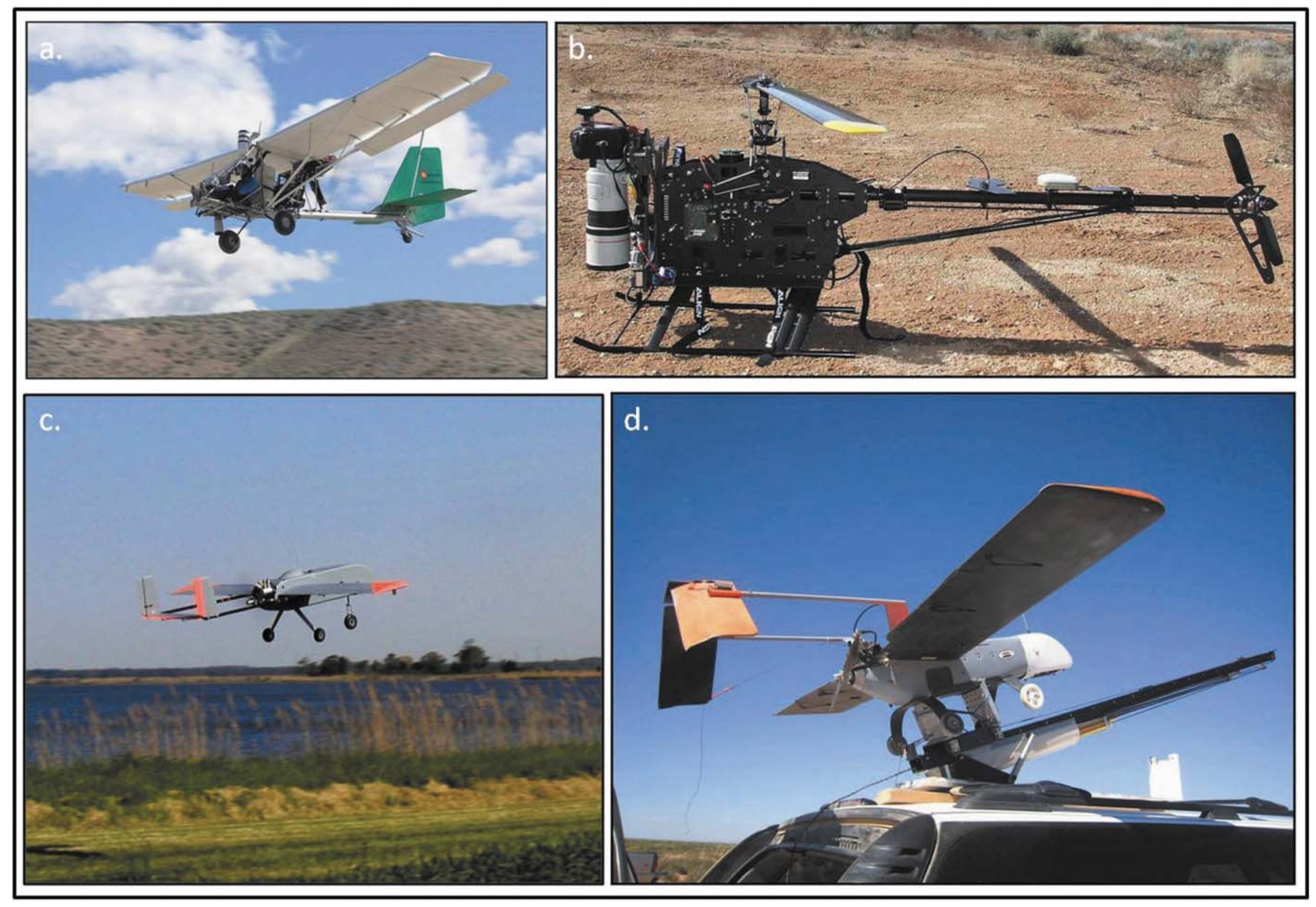

Figure 3. a, Light sport airplane on an aerial survey in northeast Nevada. Note 600-mm, image-stabilized camera lens. b, Leptron "Avenger" unmanned helicopter, single-lens reflex camera, and 300-mm, image-stabilized lens in use by Utah Department of Agriculture and Food for aerial rangeland surveys. It has image-resolution capability of $<1 \mathrm{~mm}$ per pixel (photo courtesy of Bracken Davis). c, Vector $\mathrm{P}$ unmanned aerial system from Maryland Aerospace, Inc. (photo courtesy of E. R. Hunt). d, BAT 3 unmanned aerial system on catapult. The BAT 3 is a smal unmanned aircraft $(10 \mathrm{~kg})$ used at the USDA-ARS Jornada Experimental Range for rangeland remote sensing applications. It flies a compact digital camera and a 6band multispectral camera (photo courtesy of A. Laliberte).

priority than other indicators, such as sage-grouse food forbs or the identification of invasive species. Thus, the majority of our image acquisitions have been made after development of the herbaceous canopy. If the use of canopy-cover measurements is proposed for a change-over-time analysis, users should be aware of image acquisition dates and associated long-term weather patterns, plant development, and grazing patterns relative to the acquisition dates, before deciding whether the sequential imagery can be used to test for an ecologically important change in canopy cover over time.

\section{SamplePoint}

SamplePoint facilitates point sampling of digital images. Because the sample point is always a single pixel of the image (Fig. 6a), where the image resolution is equal to or less than $1 \mathrm{mmpp}$, the analysis has a potential accuracy of $92 \%$. To use the program, we load the images from a database and apply a user-defined number of sample points over each image in either a grid or random pattern (Fig. 6b). The

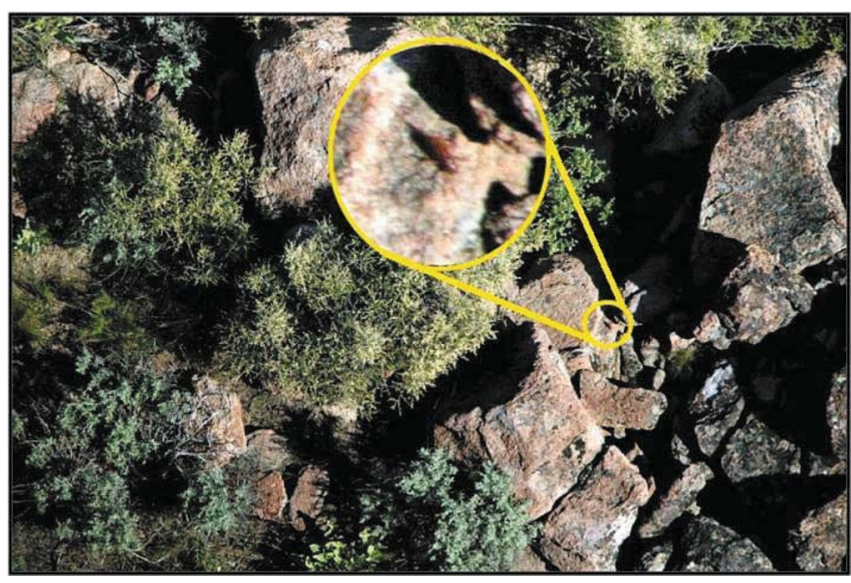

Figure 4. Mormon cricket (Anabrus simplex) captured at 1-mm per pixel image resolution from a light sport airplane at $100 \mathrm{~m}$ above ground level. 


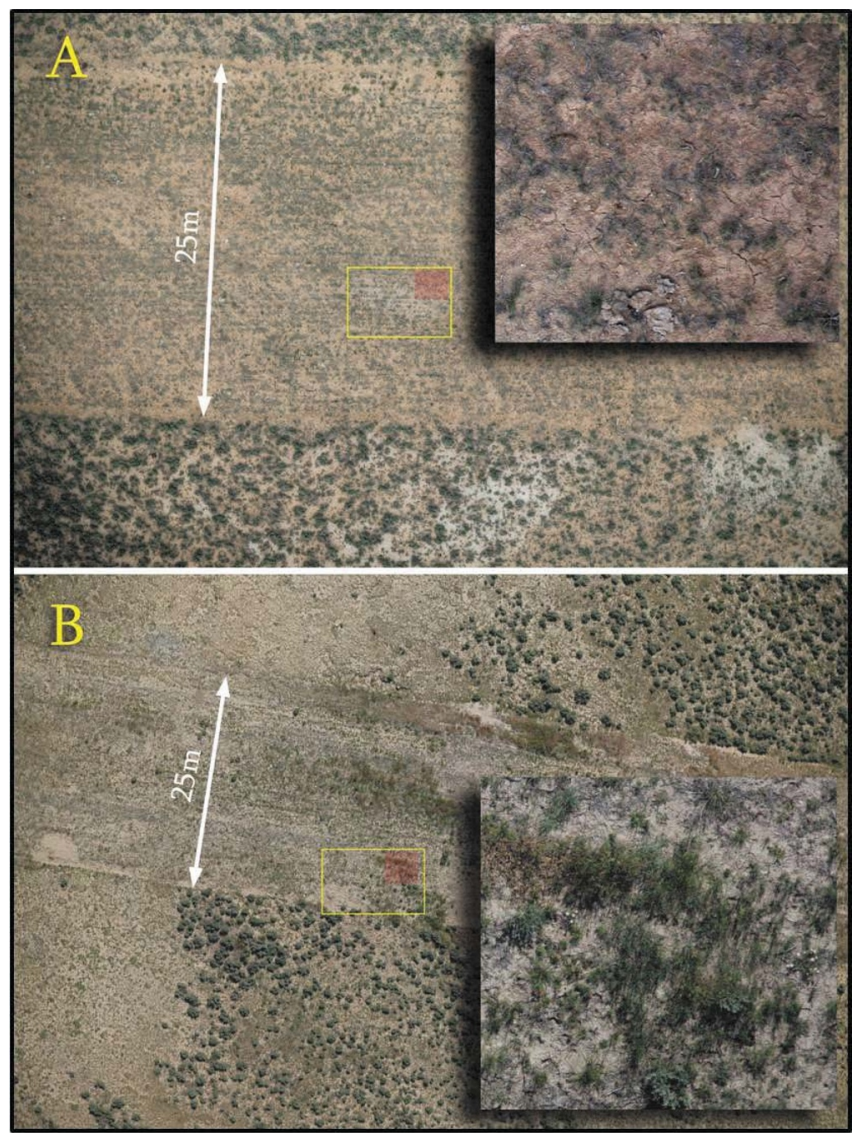

Figure 5. Aerial images of two pipeline rights-of-way in central Wyoming showing the advantage of nested images for obtaining both wide fields-ofview and highest resolution when monitoring for reclamation success. The image resolutions in $\mathbf{A}$ are $1.3 \mathrm{~mm}$ per pixel (mmpp) nested in a 13-mmpp image; $\mathbf{B}$ resolutions are $2.1 \mathrm{mmpp}$ nested in 21 -mmpp image. The yellow outline shows the location of the nested image and the shading shows the location of the inset. Bare ground and cover were measured from the 1.3- and 2.1-mmpp resolution imagery (images republished with permission).

software automatically moves from point to point when data are entered by clicking one of 30 user-defined buttons located under the image (user-defined means we label the buttons as needed). Each classification is saved to the database-no paper, pencil, or illegible handwriting. The software allows image magnification (zoom), and it can support up to three monitors (Fig. 6c), which we use to simultaneously display the image at different magnification levels. We find this feature very helpful in that we can see the sample-point pixel on one monitor, but gain understanding of the context of the pixel from the less magnified image on a separate monitor.

First-time users of 1-mmpp images are often surprised at the number of species they can identify in an image. This leads to an initial presumption that they can use SamplePoint to measure cover by species. Although this might be true for appropriately spaced woody species, users soon learn that measuring cover by life form for herbaceous species (grasses, grasslike plants, and forbs) is the more practical approach, except that the mature stages of invasive species often are distinctive.

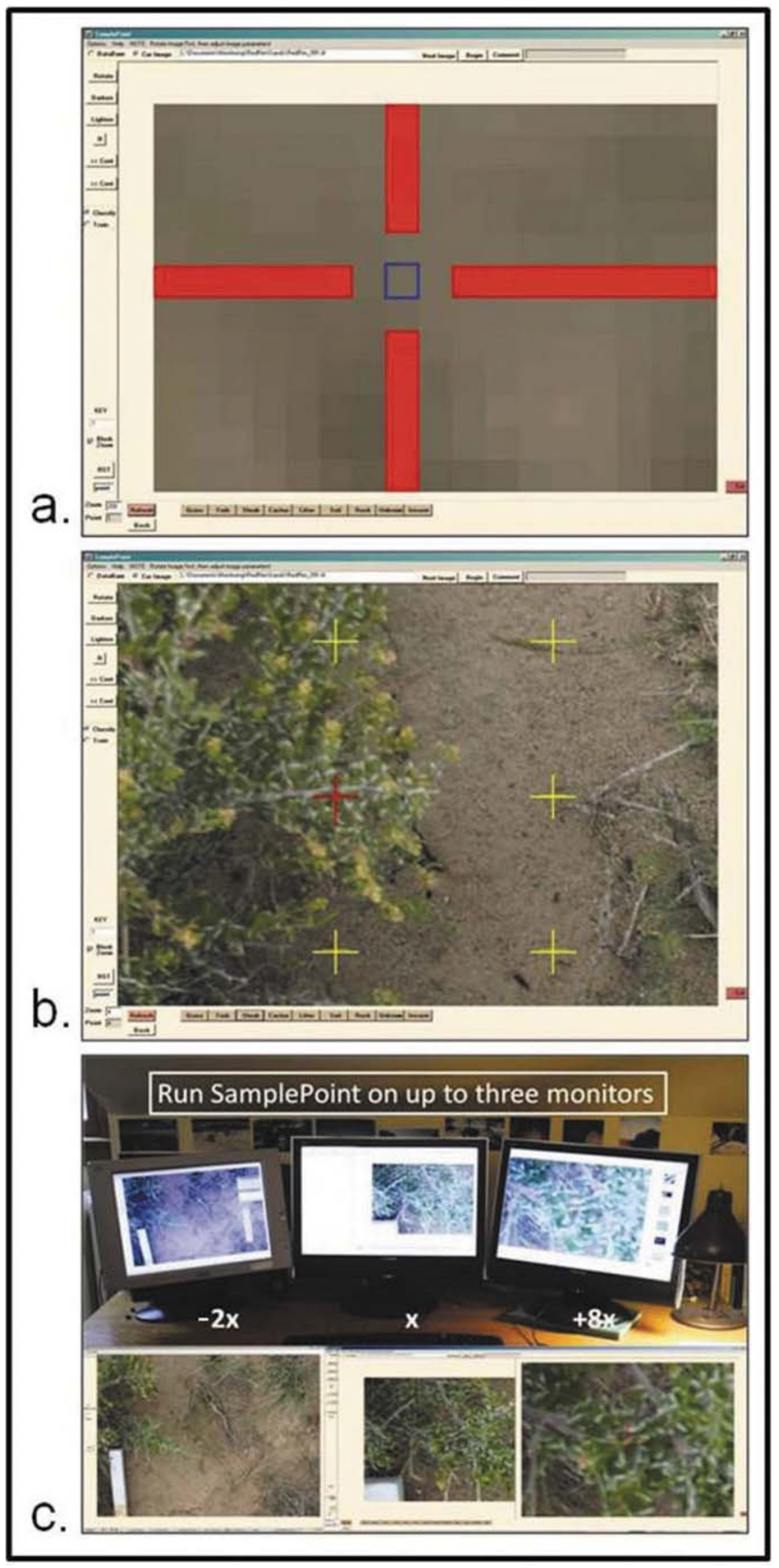

Figure 6. a, SamplePoint screen shot emphasizing the sample-point is 1 pixel at the center of a 9-pixel array within the crosshairs. Note user-labeled buttons at bottom of screen. b, SamplePoint screen shot showing a systematic grid of sample points. The active point is red. c, Three monitors simultaneously displaying an image at three levels of magnification.

SamplePoint does not correct for user biases that might occur due to personal interpretations of protocol (e.g., definition of litter) or correct for conditions such as age that can influence color perception. In fact, the variation among SamplePoint users was found to be about equal with that of users of the line-point intercept. ${ }^{6}$ (However, the study ${ }^{6}$ did not use the point-by-point training option made available 


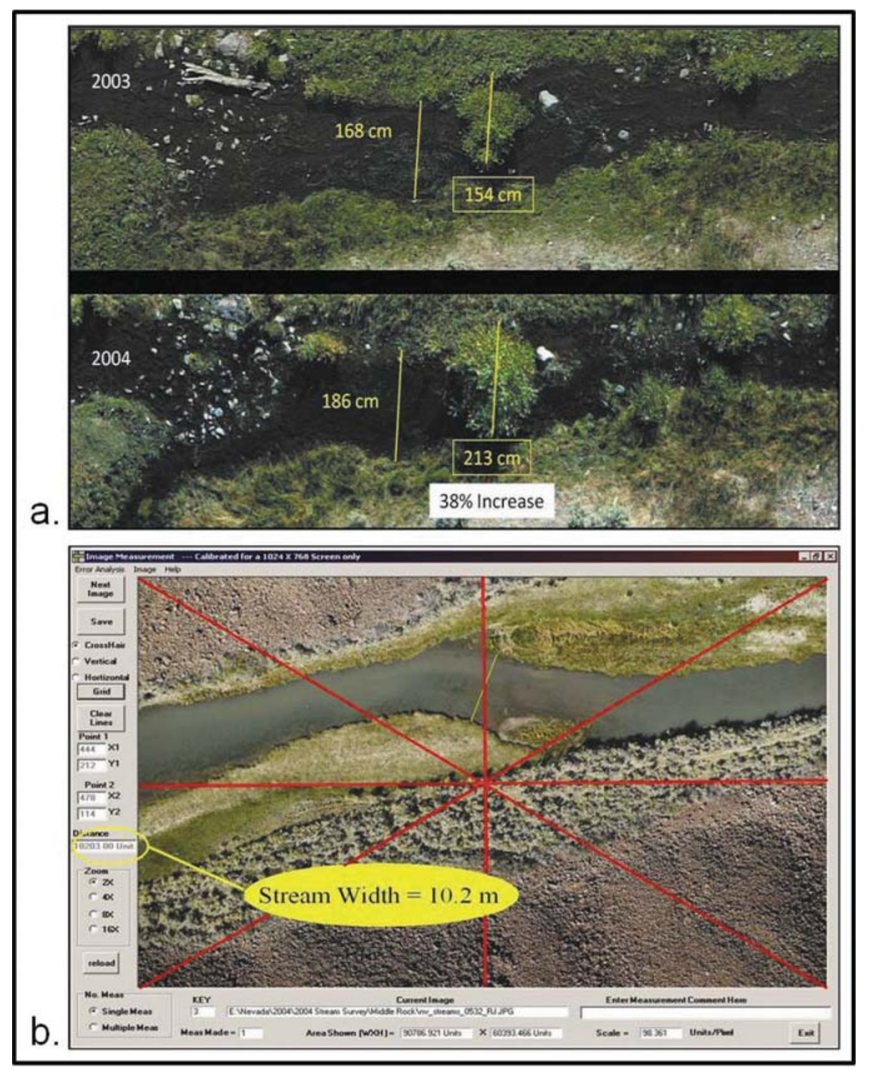

Figure 7. a, Riparian aerial images from 2003 and 2004 illustrating the use of ImageMeasurement to obtain data on linear dimensions. b, Screen shot of the crosshair pattern in ImageMeasurement.

23 October 2008 in SamplePoint v.1.45 and later versions. The effectiveness of this feature of the software in reducing among-user variability has not been tested.)

What a SamplePoint analysis does do-in contrast with conventional ground-cover measurements-is reduce analysis time, cost, and environmental stress (e.g., user is away from wind, rain, biting insects). Most importantly, users can work from a permanent photographic record. These advantages are important because they reduce user-related variation in the data. For example, given a suitable historical record, a single user can "go back in time" and make cover measurements across years at minimal cost. This removes among-observer variation across years that previously plagued condition and trend monitoring and left rangeland managers wondering whether detected differences are on the land or among the observers.

Additionally, by having multiple people use SamplePoint to analyze the same set of images, we have identified user biases in the data. When biases are found, the image data set can be reanalyzed. Data verifiability and the capability to significantly increase sampling are key advantages of using SamplePoint with image-based monitoring. Hopefully, the time will come when we will have quick, consistent, and user-friendly object-based automated image analysis that

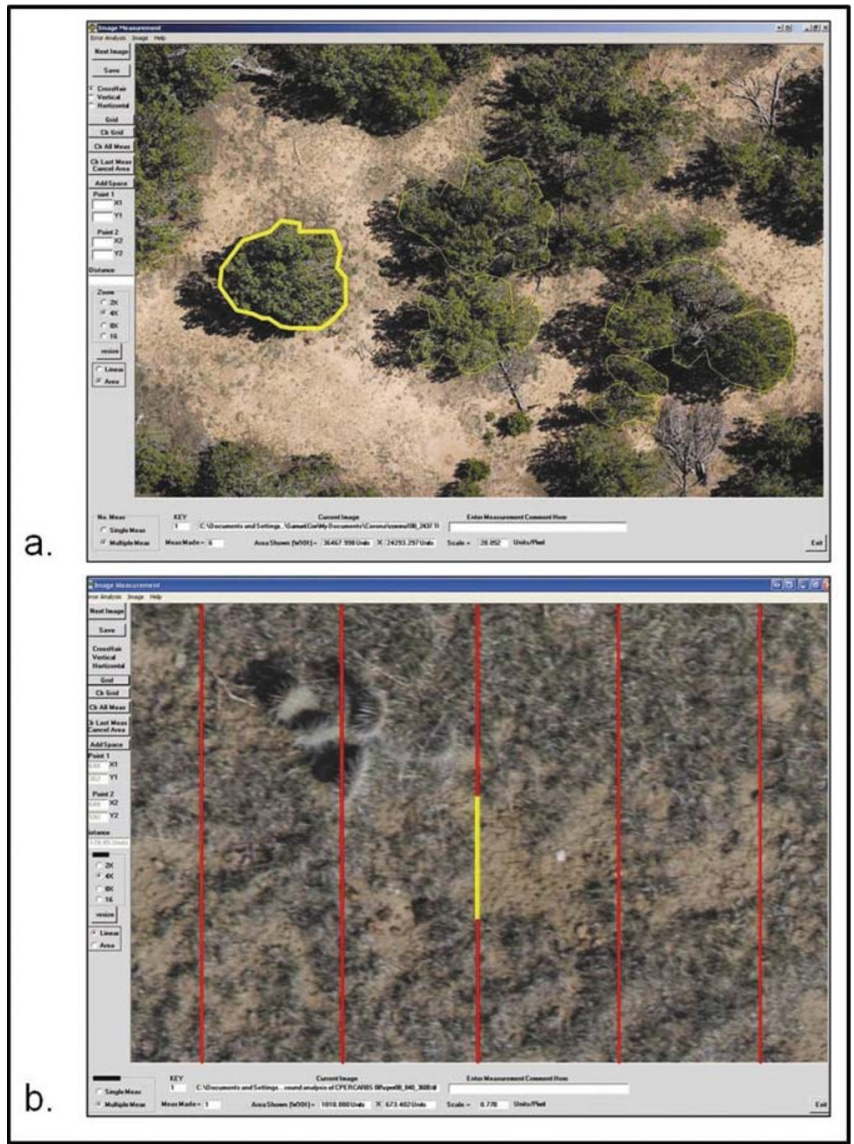

Figure 8. a, Juniper canopies delineated for analysis. Image acquired $100 \mathrm{~m}$ above ground level from a light sport airplane (LSA) at 28-mm per pixel ( $\mathrm{mmpp}$ ) resolution. b, ImageMeasurement screen shot showing a magnified image of a bare-ground patch being measured along a transect indicated using one of the ImageMeasurement grid patterns. Image acquired $100 \mathrm{~m}$ above ground level from a LSA at $<1-\mathrm{mmpp}$ resolution.

will remove personal biases from, and further speed, image analyses. ${ }^{11,12}$ Until that technological goal is reached, the manual SamplePoint method is a current and relatively accurate capability.

\section{ImageMeasurement}

ImageMeasurement can be used to measure distance or area of any feature in digital images if the resolution is known (Figs. 7a, 8a, and 8b). Several software programs facilitate image measurements, but ImageMeasurement is unique because it incorporates the exact image-resolution information for every image in a multiresolution-image data set. Images appear in an ImageMeasurement window where a user can make up to 50 distance or area measurements per image by clicking on start and stop points for distance, or on the angular points of a polygon (vertices) for area measurements. All measurements are automatically saved to a spreadsheet. The program provides several levels of magnification $(\times 2$, $\times 4, \times 8$, and $\times 16$ ) because the accuracy of measurements is 


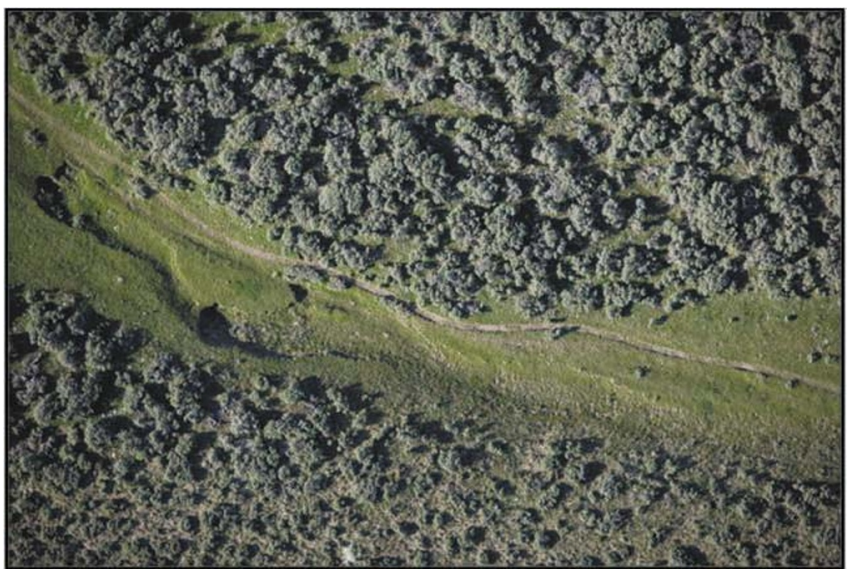

Figure 9. Multiple headcuts in what was once a stringer meadow. Image acquired $100 \mathrm{~m}$ above ground level from a light sport airplane at $\sim 20-\mathrm{mm}$ per pixel resolution.

often improved by magnification; it allows the user to see greater detail and to more accurately select the individual pixels representing the measurement points. Lower magnification increases the risk of a measurement being off by one or more pixels. A comment box can be used to record simple comments that are saved in the database with the measurements made for that image.

ImageMeasurement was conceived to measure stream width and other indicators in riparian areas. The ability to measure distance on an image for use in statistical analyses requires standardized guidelines on how and where to make measurements. Three grid patterns (crosshair, vertical, or horizontal equidistant lines) can be superimposed on an image for selection of random or systematic measurement points or used as transects (Figs. $7 \mathrm{~b}$ and $8 \mathrm{~b}$ ). ${ }^{\text {ii }}$

\section{Applications}

These tools have been effectively used to measure differences in bare ground among stocking-rate treatments on short grass prairie; to compare disturbed-land reclamation and the adjacent undisturbed native communities in sagebrush systems (Fig. 5); to detect the presence/absence and to measure cover values for multiple species of invasive plants, willow on streams (Fig. 7a), gullies in meadows (Fig. 9), shrub density as affected by fire interval, ${ }^{8}$ and sage-grouse food forbs and shrub cover in sagebrush communities. Canopy areas of juniper clumps have been measured (Fig. 8a) as a means for predicting biofuel mass. The measurement of bare ground patches detected in aerial imagery is facilitated by ImageMeasurement (Fig. 8b). Used in an appropriately designed landscape-scale sampling plan, these tools extend

\footnotetext{
"A suggested protocol for selecting and measuring points along streams was described in Booth, D. T., S. E. Cox, and G. E. Simonds. 2007. Riparian monitoring using 2-cm GSD aerial photography. Journal of Ecological Indicators 7:636-648.
}

the information obtained using other remote sensing and ground-observation tools.

\section{Conclusions}

"You can't manage what you can't measure" is an oftenquoted saying reminding us that repeated measurements (monitoring) are important for understanding status relative to defined goals. Natural resource surveys have been hampered by the high cost of conventional ground methods, by variation in collected data, and by a lack of statistical design and rigor in monitoring efforts. These problems have reduced data utility - often nullifying any value of the measurements. Where samples are too few to avoid a high risk of a false conclusion, where variability in the data might be equally due to observer differences as to differences over time, and where there is no way to verify the accuracy of an observation or measurement, can we claim the ability to manage the thing we have attempted to measure?

Suppose that because of low sample numbers and data variation or both, increases in bare ground over time go undetected with no change in management until gullies are seen on the landscape; then, is management directed at bare ground or gullies? Similarly, attempts at landscape-scale ecosystem management have been disadvantaged by the limitations imposed with subjective selection of allotment or watershed study areas, and with the impracticality of doing otherwise. These challenges defined a need for improved monitoring technologies. More progress is needed; but by using the tools and methods described in this article, with carefully crafted, statistician-approved sampling plans, resource managers now can reduce sample variation, increase sample numbers, and, by using systematic ground and aerial digitalcamera sampling, take a more objective approach to landscapescale monitoring. SamplePoint and ImageMeasurement use a database approach that facilitates precision measurements from images in a simple, straightforward way that increases the accuracy and speed of image analysis. We have demonstrated that image resolution must be consistent with the task and desired accuracy of planned measurements. If the appropriate imagery is used by people with appropriate onthe-ground experience, then our programs are effective tools for objective detection of change-over-time across extensive areas in the vegetation types common to the western United States.

\section{Acknowledgments}

We have not directly cited our own work. Those publications are available at http://www.ars.usda.gov/pandp/people/people. $\mathrm{htm}$ ?personid=536\#Publications. Programming for SamplePoint and ImageMeasurement was done by Robert D. Berryman. Aerial images were acquired by CloudStreet Flying Service, Fort Collins, CO (http://www.cloudstreet.net/index.html). Mention of trade names is for informationonly and does not imply an endorsement of products or services to the exclusion of similar products or services of equal quality. 


\section{References}

1. West, N. E. 2003. History of rangeland monitoring in the U.S.A. Arid Land Research and Management 17:495-545.

2. Interagency Technical Team (ITT). 1996. Sampling vegetation attributes, interagency technical reference. Denver, Colorado, USA: US Department of the Interior, Bureau of Land Management-National Applied Resources Science Center. Report No. BLM/RS/ST-96/002+1730. 171 p.

3. West, N. E. 1999. Accounting for rangeland resources over entire landscapes. In: D. Eldridge and D. Freudenberger [EDS.]. Proceedings of the VI International Rangeland Congress. Aitkenvale, Queensland 4814, Australia. Townsville, Queensland, Australia: VI International Rangeland Congress, Inc. p. 726736.

4. Cooper, W. S. 1924. An apparatus for photographic recording of quadrats. Journal of Ecology 12:317-321.

5. Louhaichi, M., M. D. Johnson, A. L. Woerz, A. W. Jasra, And D. E. Johnson. 2010. Digital charting technique for monitoring rangeland vegetation cover at local scale. International Journal of Agriculture and Biology 12:406-410.

6. Cagney, J., S. E. Cox, And D. T. Boоth. 2011. Comparison of point intercept and image analysis for monitoring rangeland transects. Rangeland Ecology \& Management. 64:309-315.

7. West, N. E. 2003. Theoretical underpinnings of rangeland monitoring. Arid Land Research and Management 17:333-346.

8. Moffet, C. A. 2009. Agreement between measurements of shrub cover using ground-based methods and very large scale aerial imagery. Rangeland Ecology E' Management 62:268-277.
9. Dunimay, M. C., J. W. Karl, S. Schrader, N. Baquera, and J. E. Herrick. Range and pasture monitoring using high resolution aerial imagery: a repeatable image interpretation approach. Environmental Monitoring and Assessment (in press).

10. Weber, K. T., F. Chen, D. T. Booth, M. Raza, K. Serr, and B. Gokhale. Comparing two ground-cover measurement methodologies for semiarid rangelands. Rangeland Ecology E Management (submitted).

11. Luscier, J. D., W. L. Thompson, J. M. Wilson, B. E. Gorham, And L. D. Dragut. 2006. Using digital photographs and object-based image analysis to estimate percent ground cover in vegetation plots. Frontiers in Ecology and the Environment 4:408-413.

12. Laliberte, A. S., A. Rango, J. E. Herrick, E. L. Fredrickson, AND L. Burkett. 2007. An object-based image analysis approach for determining fractional cover of senescent and green vegetation with digital plot photography. Journal of Arid Environments 69:1-14.

Authors are Rangeland Scientist, USDA-ARS, High Plains Grasslands Research Station, Cheyenne, WY 82009, USA, Terry.Booth@ars.usda.gov (Booth); and Natural Resource Specialist, USDI-BLM, Wyoming State Office, Cheyenne, WY 82009, USA (Cox). This work was supported by USDA-ARS and through grants from USDI-BLM, Wyoming State Office to DTB. 